\title{
Atlantis
}

Critical Studies in Gender, Culture \& Social Justice

Études critiques sur le genre, la culture, et la justice

\section{In Defense of Safe Spaces: A Phenomenological Account}

\section{Jina Fast}

Volume 39, numéro 2, 2018

URI : https://id.erudit.org/iderudit/1064069ar

DOI : https://doi.org/10.7202/1064069ar

Aller au sommaire du numéro

Éditeur(s)

Mount Saint Vincent University

ISSN

1715-0698 (numérique)

Découvrir la revue

Citer cet article

Fast, J. (2018). In Defense of Safe Spaces: A Phenomenological Account. Atlantis, 39(2), 1-22. https://doi.org/10.7202/1064069ar

\section{Résumé de l'article}

The notion of "safe space" is one example of a theoretical and pedagogical resource grounded in studies of marginalized experiences that has recently undergone backlash in dominant culture and the academy. In this essay, I offer a defense of safe spaces using the theoretical resources of phenomenology and offer suggestions for moving past the dichotomy of safe versus unsafe space. I argue that safe space should be understood not as static and acontextual, as truly "safe" or "unsafe," but through the relational work of cultivating such spaces. Furthermore, far from restricting dialogue in the classroom, safe spaces encourage dialogue through requiring students to utilize critical thinking in their exchanges and through supporting marginalized students whose positions and humanity often fail to be recognized in dominant spaces.
Ce document est protégé par la loi sur le droit d'auteur. L'utilisation des services d'Érudit (y compris la reproduction) est assujettie à sa politique d'utilisation que vous pouvez consulter en ligne.

https://apropos.erudit.org/fr/usagers/politique-dutilisation/ 


\section{In Defense of Safe Spaces: A Phenomenological Account}

Jina Fast is a Lecturer in Women's and Gender Studies and Philosophy at West Chester University.

Abstract: The notion of "safe space" is one example of a theoretical and pedagogical resource grounded in studies of marginalized experiences that has recently undergone backlash in dominant culture and the academy. In this essay, I offer a defense of safe spaces using the theoretical resources of phenomenology and offer suggestions for moving past the dichotomy of safe versus unsafe space. I argue that safe space should be understood not as static and acontextual, as truly "safe" or "unsafe," but through the relational work of cultivating such spaces. Furthermore, far from restricting dialogue in the classroom, safe spaces encourage dialogue through requiring students to utilize critical thinking in their exchanges and through supporting marginalized students whose positions and humanity often fail to be recognized in dominant spaces.

Keywords: pedagogy; gendered spaces; phenomenology
W hat happens on the college campus rarely stays there. Rather, the disputes and lived experiences that arise on campus open up into the shared social world to inform contemporary debates about identity, privilege, oppression, and freedom. The past few years in the US, Canada, ${ }^{1}$ Great Britain, ${ }^{2}$ and many other nations, we have witnessed student activism expose contradictions present in the university system. Generally, universities in the contemporary era aspire to appear diverse. Yet, without radical commitment to reimagining the system they often fail to practically and meaningfully represent the perspectives of historically marginalized groups. Historically marginalized students do not merely observe this contradiction, they feel it: the students' presence is felt to be tolerated but not desired; they are permitted to be there, but with this granted opportunity are expected to express gratitude rather than challenge. When students refuse to adhere to these implicit expectations and instead challenge the status quo composition and traditions of the university, their perspectives may be trivialized, their suggestions mocked, and the theoretical resources they employ dismissed.

The notion of "safe space" is one example of a theoretical and pedagogical resource grounded in studies of marginalized experience that has recently undergone notable backlash in dominant culture and the academy. In feminist, queer, and critical race movements, an understanding of safe space has developed that is concerned specifically with keeping marginalized groups free from the violence and harassment they routinely experience in dominant spaces. Many educators have adopted this concept to consciously (re)create their classrooms as safe space, so that all students-including those with marginalized identities_are free to "unravel, build and rebuild 
knowledge" (Stengel and Weems 2010, 507).

However, because the phrase "safe space" has been so widely adopted, it has arguably become an "overused but undertheorized metaphor" (Barrett 2010, 1). The term "safe space" has been used to refer to "separatist" safe spaces in queer, anti-racist, and feminist communities, "inclusive" safe space classrooms, and safe spaces in which (non-human) objects are central (Boostrom 1998; Barrett 2010). Further complicating our analysis, the term "safe space" is often invoked in public discourse to signify either (1) a progressive commitment to recognizing and including the lived experiences of marginalized groups or (2) an encroachment upon the rights of the abstract citizen's freedom of speech. In invoking "safe spaces" to perform a political perspective-democrat or republican, radical or neo-liberal-popular essayists, political pundits, university administrators, and even many academics fail to understand the history and diversity of the kinds of safe spaces that can exist and the complex theoretical commitments underlying calls for safe spaces.

In this essay, I offer a defense of safe spaces and suggestions for moving past the dichotomy of safe versus unsafe space. I argue that safe space should be understood not as static and acontextual, as truly "safe" or "unsafe," but through the relational work of cultivating these spaces. Understanding safe spaces in this way reveals several tendencies. First, and as an important starting point, it reveals that space is not neutral. Dominant spaces are discursively constructed as safe for normative social identities (white, male, heterosexual, middle-class) through making public space unsafe for marginalized identities. Second, focusing on the relationality of safe spaces shows their inherent paradoxical structure. Cultivating safe space requires the foregrounding of social differences and binaries (safe-unsafe, inclusive-exclusive) as well as recognizing the penetrability of such binaries. Renegotiating these binaries is necessarily incomplete; a safe space is never completely safe, for it cannot ever truly be. We can and should, however, encourage the critical cultivation of what we may call safer spaces as sites for negotiating difference, challenging oppression, and disrupting and transcending misrecognition. Moreover, conceiving of safe spaces in this manner neutralizes prevailing criticisms of safe spaces such as the claims that safe spaces are averse to difference, silence normative identities, and further the divisions between students.

For the purposes of this piece, I am interested in exploring what dialogue between those of us who work within and across critical race theory, queer theory, and feminist theory can offer to university policies regarding and pedagogical practices in creating inclusivity. Here, I am not interested in weighing in on the consequences students or professors have faced in advocating for or against safe spaces. Instead, using a phenomenological analysis in the first section, I will draw attention to the process of constituting space as safe or unsafe for social groups through dominant discourse. In the second section, I respond to common criticisms of safe spaces by unpacking a 2015 dispute at Yale University regarding the responsibility faculty and administrators have in fighting against the misrecognition and abjection of marginalized groups. Here, I use the Yale case merely as an example. My argument can be extended to consider similar debates that have arisen on many college campuses across the U.S. (and many other nations) and in mainstream punditry criticism following the recent U.S. presidential election and rise in nationalist movements globally. Additionally, to provide a counter model to the example from Yale, and for descriptive purposes throughout this essay, I will draw from my own experiences in the classroom in creating safe $(r)$ spaces for my students. My examples are to some degree course material specific, but I believe they will offer concrete references for what I mean as I argue for the practice of creating safe $(r)$ spaces in class and on the university campus more broadly.

In the final section, I will address a criticism specifically directed at queer theories and theorists, namely that arguing for the recuperation of safe space for marginalized groups contradicts the deconstructionist epistemological position queer theory holds regarding 
identity. In other words, it is assumed that the argument for the necessity of creating safe space for marginalized populations relies on naming the marginalized identity that requires protection from the dangers of the dominant identity, thus in effect reifying both identities. Queer theories, by contrast, reveal the inherent instability of identity positions, presumably negating the possibility of establishing the group as a stable group to protect. I contend that this presumed contradiction rests on at least two misunderstandings. The first is confusion between theory and practice, where the inherent instability of social identity is taken to mean we can never experience ourselves as belonging to a gender group, racialized group, class group, etc. While the status of gender and race may be ontologically troubled, practically, we are gendered and racialized through the gazes of others and through our affective relationship(s) to ourselves. The second misunderstanding relies on the misconception of the ontology of safe(r) spaces themselves that I address throughout, namely that safe space can ever be fully realized and that marginalized populations can ever be fully protected. If full and perfectly realized protection is not the aim of the work of creating safe(r) spaces in the first place, then using queer theories as instructive for thinking about safe space does not produce a contradiction but rather functions as a meaningful foundation for bridging the gap between theory and practice.

\section{Fear and Lack of Safety}

The idea of safety is relational, fundamentally related to the actual and perceived threat of violence. To feel safe is to move through space without fear of violence; while to feel unsafe is to experience one's vulnerability to violence. While we often do not perceive violence as something with which we continually engage, it is enacted upon us in a way that interrupts daily life. Moreover, the anxieties that arise in the expectation of intrusion of the unsafe reflect gendered, sexual, and racialized power relations that are effects of a system of structural violence (Koskela 1997). The effects of systematic and structural violence are far- reaching and are not limited to merely the physical risk of violence. In terms of mobility, the fear experienced by vulnerable bodies works to allow some bodies to exist and move freely in public spaces through restricting the mobility of other bodies to private spaces (Ahmed 2003). Consider the work fear performs in the lives of persons who encounter regular harassment at work, in the military, in education or in the street and the behavioural adaptations fear motivates in attempts to create provisional safe space for the self. If she is harassed regularly in the street while she jogs, she may choose different routes or pay money to join a women's-only gym; if at work they may cease to volunteer for projects that put them in close contact with their harasser or they may avoid networking opportunities, including happy hours and retreats that place them in informal settings with their harasser; if in education, he may miss class, hold back on participating in order to not call attention to himself, have to put up with harassment in order to advance his career or give up his dream in order to be safe from harassment.

In all of these examples, fear of harassment functions to restrict the movements of the harassed. But the effects of restricted mobility extend beyond the lives of the harassed, producing benefits for social groups less likely to be harassed. The affective experience of fear then discursively reiterates public space as masculine space, white space, heterosexual space, through the denying of public space as safe for women, persons of colour, and queers. Take for example the parietal rules of the mid-twentieth century which restricted women on college campuses to their dorms, allegedly to keep them safe from potential assault. The impact of said rule was personal, as individual women were unable to leave their dorms after curfew, political in that the rule specifically applied to a gendered caste of peoples, and spatial, as space on the college campus is reiterated as masculine and thus unsafe for feminine bodies and the movement of femme people. Today we continue this norm of public space as masculine by routinely teaching girls and women special rules to keep them safe without attending to what makes them unsafe in dominant spaces (Stengel 2010). In- 
stead of investigating the roots of the constitution of space as safe or unsafe, both then and today, we attempt to dispel from public space those to whom we fail to extend safety as possibility. The result is that based on personal experiences and social cues, people develop maps of where they feel threatened, which can have effects on one's economic, social, and political being (Valentine 1989). Institutional and social norms demand this process of mapping, encouraging some people to avoid certain spaces by designating them unsafe, thereby controlling how bodies relate to public space and to one another.

We can further consider what it means to feel safe or unsafe through a consideration of comfort and discomfort. In The Cultural Politics of Emotions (2004), Sara Ahmed argues that comfort is experienced not merely as emotional, but as the social-spatial fit between body and object. For example, your comfortable chair may be awkward for me, and my favorite cotton T-shirt made soft by repeated wear by my body may restrict your movement or hang too loose. In both instances, the shape of the body imprints upon the object that becomes comfortable for that body, in effect making the surface of the body disappear. The body as body reappears only when it fails to fit. My body appears as I squirm in an attempt to make your comfortable chair fit my awkward body; your body appears when the sleeves of my T-shirt restrict the movement of your arms or when it slides off the shoulders. The awkwardness, however, is not experienced as merely a disconnect in fit, but is felt as an awkwardness of the body itself. I may know upon reflection that the discomfort results from the incompatibility of my body and your chair; but I feel the discomfort as an awkwardness of my body. Similarly, social norms become a form of public comfort where some bodies are able to extend into spaces that have already been carved out for them. Because the space has been carved out through the repeated reiteration of norms and values, space is assumed to simply be for them naturally and the work of creating space disappears. However, just as individuals do not have pre-existing identities, neither do spaces; space is not naturally "straight," "white," or "masculine" but rather is actively produced (Binnie 1997).

Like the comfortable chair or T-shirt that have acquired their shapes through the repetition of the body inhabiting it, the discursive creation of public space creates bodily space wherein some may pass safely, for example the heterosexual couple holding hands, and others, the lesbian couple engaging in the same act, to feel uncomfortable. Queer subjects, when faced by the normative comfortability of heterosexuality may feel disoriented, out of place or estranged (Ahmed 2004). This disorientation is experienced in part due to the threat of violence that accompanies one's failure to "fall in line," but is also an effect of being denied access to participating in the shaping of public space. The repetition of heterosexuality, whiteness, and masculinity is naturalized in public spaces on billboards, in music, film and television, in displays of heterosexual intimacy, and through the protection of some within dominant institutions by actively or passively abandoning others. Those who experience comfort in the world, however, tend not to recognize the world as a world of norms they have taken in and are reflected all around them. Norms, like the body in my previous examples, disappear for those who seamlessly slide into normative space, only to reappear for those who do not "fit." For some queer theorists and queer identified peoples, embracing discomfort is desirable because comfort (and even the project of happiness itself) is associated with assimilative practices, where one who happens to be queer, of colour, or a woman is valued if they internalize and express allegiance to normative values (Ahmed 2010). Others, however, embrace the extension of normativity in order to be included in the "safety" of fitting in.

Nevertheless, while safety requires freedom from physical violence and the fear of physical violence, it is not adequate to provide safe space for marginalized groups. Additionally, safety entails a positive conception, realized through recognition as human, as worthy of safety and protection, and as valuable in creating the shared world. When marginalized groups are denied physical and psychological right to remit- 
tance from violence, they are also denied right to recognition and instead often suffer from misrecognition. In the next section, I will unpack a 2015 controversy at Yale University over recommendations regarding Halloween costumes to question who is responsible for mitigating the harms of misrecognition, as well as to further the use of a phenomenological, deconstructivist methodology in understanding the need to take seriously as a resource the active creation of safe(r) spaces.

\section{Agency and Choice}

In the fall of 2015, the Intercultural Affairs Committee at Yale University sent an email to the student body advising them to avoid "culturally unaware or insensitive choices" in dressing for Halloween. ${ }^{3}$ The recommendations included specific practices to avoid, such as modifying one's skin tone, as well as general questions one should ask in the process of choosing a costume, such as: "Is the humour of my funny costume based on 'making fun' of real people, human traits or cultures?" In response to this initial email, 4 Professor Erica Christakis, an expert in early childhood education, penned her own email acknowledging the "genuine concerns of personal and cultural representation," but questioning the interventionist strategy of administrators in attempting to shape the norms of Yale students, the Yale campus, and perhaps by extension the broader community. Specifically, Christakis appears concerned about the space available for students to develop an understanding of themselves as free and empowered. On a charitable reading, she seems to imply that if students are told how to act, they will fail to become internally connected to anti-racist principles because these are not adopted as their principles. In other words, Christakis suggested that rather than anti-racist norms being legislated by outsiders (framed as faculty, administrators, and parents), students should come to adopt them as their values through a free process of rigorous dialogue and critical reflection with students who believe racist Halloween costumes to be harmful. We may frame Christakis' argument as vaguely Pla- tonic both in terms of the form she argues for, a Socratic dialogic method, and also the goal, namely internal connection to the norms rather than external enforcement of the adoption of values. Yet, in providing such a sympathetic reading of Christakis' position we are failing to consider the phenomenological horizons and history in which the argument is grounded, as well as her explicit failure to consider the power discrepancies that exist between groups of students on a campus that is not a neutral space. Considering the broader context enables a better understanding of what is at stake here for marginalized racialized groups which experience harm as an effect of racist Halloween costumes. Additionally, these events at Yale allow for consideration of the ways in which the politics of the campus and classroom extend into off-campus space(s) and then back on to campus. Racist Halloween costumes, while not unheard of on college campuses, are more often worn to university-associated fraternity and sorority parties. Thus, the question of how universities should respond is not necessarily a consideration of that which is framed as "on campus" behaviour, but rather invokes a complex consideration of what constitutes university space and where Yale students are in fact constituted by their identities as Yale students and where these identities are left behind. While presumably an unintended effect of Yale's administration, the recommendation that Yale students avoid racist costuming functions to disrupt the binary distinction between the "on-campus" and "off-campus." Here, the off-campus still invokes the on-campus in that the relationships of students in sororities and fraternities are established through entering a shared oncampus space. Furthermore, those invited to Halloween parties thrown by fraternities and sororities are often other university students met through oncampus activities. The students' relations to one another here are internally constituted and mediated by the fact that they share a university identity cemented by and through the on-campus space of Yale. Yet, the students are also constituted externally as Yale students based on reference to the space by potentially being named by non-Yale persons as Yale students. The reference invoked in a hypothetical headline 
"Yale frat threw a racist-themed party" is constructing a complex identity for Yale students that does not rely on mere present occupation of the Yale campus, but rather renders ambiguous where the space of Yale begins and where it ends. 5 Nevertheless, bracketing this binary deconstruction in the abstract, the case at Yale is of special significance in that the debate about off-campus behaviours is hashed out on campus in many different kinds of spaces, some public (the lawns of Yale campus), some private (residence halls), and in classrooms.

Now, regarding Christakis' specific argument, first, we must acknowledge the university campus itself as a historically racially exclusive and gender exclusive space. At Yale, the first black students admitted in the nineteenth century were not permitted to earn credit or to speak in class. Meanwhile, moving into the twentieth century, women and people of colour were rarely admitted until the 1960s, and it was during the sweeping national integrationist education movement that Yale had to confront its own "neutral” standards used for admittance (Karabel 2005). By the 1965-1966 school year, the Admissions Committee at Yale revised its admission procedures through considering that "cultural deprivation" and not lack intelligence can have an effect on black students' SAT scores and grade point averages (Karabel 2005). In short, Yale in the 1960s acknowledged that social organizing principles and institutional discrepancies in access to resources affect black students' development and thus in order to encourage greater racial diversity in their student body adapted their admission procedures to take affirmative action. Arguably, such a move is quite progressive, but as critical race theorists such as Lewis Gordon (1999), Franz Fanon (1967), and Paget Henry (2000) have shown, admittance into white space does not entail acceptance of blackness. In the 1960s and today, the majority of professors are white, the theories and perspective taught derive from white people, and what is considered disruptive versus instructive is often defined through the politics of the white gaze. We can see this not just in terms of how the university administration is chastised for daring to make Yale a bit more comfortable for students of colour, but also in how students who responded to Christakis' email were treated in the media coverage. One student who confronted Nicholas Cristakis for failing to fulfill his responsibilities as a professor and as the head of residency at Silliman Hall where he lived among students with his wife was quickly and diminutively dubbed "The Shrieking Girl"6 and, due to the subsequent harassment she faced as a woman of colour calling for safe(r) spaces at Yale, was compelled to delete her online profiles.

Second, by not mentioning race, Christakis fails to consider the racialized horizons in which racist costume-wearing occurs. Instead, she invokes a seemingly "boys will be boys" attitude regarding the responsibility students have to not harm one another, thus rendering the harm enacted unimportant. This move is also not neutral, but reinforces a protection of whiteness by emptying white students of responsibility for their actions and erasing the harms enacted against students of colour. The students who feel free to engage racial cross-dressing are not without a racialized identity - they are white-and the students whose identities are adopted as costumes are students of colour. The "why" question (i.e. why do white students engage in wearing racist costumes for fun?) is also relevant here. White students generally can adopt "other" racialized identities in play because they are repeatedly framed as lacking racial identity. Racial identity is less meaningful to them in their interpretation of what it means to be identified because it has not posed a problem for them. This, of course, does not mean that their identity is truly less meaningful in terms of effects that unfold over and within their lives. Rather, whiteness as neutral/non-identity (and as desirable and good) has been constructed within a contemporary history where blackness has been denigrated and reduced to the status of the sub- or nonhuman (Fanon 1967; Henry 2000; Gordon 1999, 2015). The neutrality and positivity of whiteness and white peoples relies on the constant (re)iteration of blackness as lack of being and black peoples as less than human. This dependent relationship of whiteness on blackness is performed through anti-black 
language, anti-black systems of law and criminal justice, anti-black scientific discourse, and through the deployment of anti-black cultural images. Antiblack cultural images such as the jezebel, the mammy, the sapphire, the savage or brute, the thug, the Uncle Tom, and the minstrel man, have been used simultaneously throughout history to render black people as foolish and thus content with oppression and to frame black peoples as dangerous threats to white people. The anti-black costumes Yale sought to address in their recommendations to students tend to fall into one or more of these categories as white students "dress up" as "pimps," "hoes," "gang members," "harem girls," "Native Savages," and so forth. Culturally appropriative costumes, while not necessarily rendering people of colour as dangerous or deviant, function instead to disregard the seriousness and the value of the cultures of peoples of colour. Through the general cultural acceptance and active defense of the right of white students to wear as costume Saris, or headdresses, or dashikis, the deep, internal histories and symbolic coherency of Indian, First Nations, and African cultures are rendered foolish, inferior, and infantile. The effect, here, is not just the denigration of people of colour's cultures, but the uplifting of intelligent and properly cultured space as white. Furthermore, students of colour do not experience this belittling merely on the level of the symbolic, but as a direct abuse on selfhood. For if I am black, and black culture is decreed as inferior, stupid, infantile, and dangerous, then I am rendered in my very being inferior, stupid, infantile, and dangerous.

Despite these issues with Erica Christakis' argument, the portion of the email to which students themselves most directly objected was attributed to Christakis' husband, Nicholas Christakis, who is also a professor and residential head of college at Yale. Erica Christakis wrote, "Nicholas says, if you don't like a costume someone is wearing, look away, or tell them you are offended. Talk to each other. Free speech and the ability to tolerate offense are the hallmarks of a free and open society." In the students' responses to the Christakises standpoint, we can unambiguously recognize their frustration with the lack of attention to the social geography of space, the effect of which sets the conditions for the possibility of recognition available to students based upon race, class, gender identity, and sexual orientation. The Christakises' positions within the university are somewhat unique in that not only do they interact with students in the classroom, but also as residential heads of college; they therefore play substantial roles in the cultivation of space for students both inside and outside of the classroom. Thus, in the students' protests, open letters and essays, we find not merely a rebuttal of the Christakises' positions, but a call to reconsider the expanded responsibility that faculty who live among students have in creating safe space for marginalized students. To understand why this might be a responsibility of those with formal and social power in the university setting, I suggest we look to the consequences of misrecognition and the possibilities existing for marginalized students to achieve reciprocal recognition. While the problem for marginalized and stigmatized groups can be quite obvious to those who work within and theorize from critical race, feminist, and queer deconstructionist perspectives, it is still not regularly acknowledged in dominant space, which in turn perpetuates misrecognition.

Contemporary recognition scholarship (Young 1990; Gutmann 1994; Honneth 1992) relies centrally on the Hegelian concept of mutual recognition that ideally allows citizens to operate as equals within the political world. Citizens, Hegel proposes in The Phenomenology of Spirit, want more than fair distribution of physical and intellectual resources; they desire confirmation of their humanity in its particularity and are willing to risk their lives to achieve it. While debates in recognition scholarship persist over the role social identity plays in conditioning the positioning of the subject internal to or outside of the struggle for recognition, most scholars in the field share the conviction that recognition is a crucial human good that serves as a precursor for justice in a pluralist and democratic society. For a society, then, to be deemed good or fair it seems a society must offer its citizens equal opportunities for public and accurate recognition. If it fails to do so, at least two injurious effects 
arise. First, some human beings are denied access to something for which all humans strive and, second, the act of seeking recognition itself becomes a degrading experience for marginalized individuals in that one must ask for recognition from those who despise them.

As we attend to the active constitution of shared social space, we find that despised groups who are abjected or viewed through stereotypes must negotiate space that is collapsing around them in order to prove they deserve to be recognized as human beings with value. Significantly, these groups must seek recognition not from within their own group, but from those who despise them and who benefit from despising. Recognition, then, is on the one hand a useful framework because it exposes the interconnection between individuals and social groups. On the other hand, however, we must question whether the dominant recognition framework is merely a pathway to assimilation. Women, for example, resent the idea of casting gender as irrelevant to identity in that it obscures a history of gender inequality and encounters with sexist norms and barriers which produce objective and subjective effects. They seek to be understood, to be read or recognized as women, without being reduced to their gender and without being forced to internalize masculine norms to be valued. Similarly, persons who happen to be black, do not want race to be deemed as irrelevant to their lived experiences, concrete possibilities, and identities. But neither do they want to be reduced to their racial identities or be forced to internalize whiteness as normative and repudiate the value of blackness and black identities. Nevertheless, recognition as it is often conceived and practiced within dominant spaces does not on its own provide for retention of marginalized identity without either reduction to said identity or assimilation to the normative viewer's position.

Safe spaces, by contrast, can retain this tension and thus prove to be much more complex than merely offering absolute protection to marginalized identities at the expense of normative ones. Through the active cultivation of safe space in the classroom, marginal- ized students are able to circumvent the requirement that they first defend their existence as human prior to participation in public space. Furthermore, classrooms cultivated as safe spaces disrupt the theoretical presupposition of public space as "for everyone" through consideration of the importance of social identity. Finally, safe spaces can begin the reparative work of reclaiming the humanity and value of self for marginalized groups not through rejecting critical thinking and openness, but rather through requiring it to understand and deconstruct systematic relations of power, identity, and oppression.

To return to the Christakises' argument: Nicholas Christakis's statement that students should be able to talk to one another positions the blame for continued misrecognition and the responsibility to speak up with the student who is perpetually misrecognized. Christakis' point fails to acknowledge, however, the discrepancies in power that exist between students who reside in space as non-normative or anti-normative and those who are reflected in the accepted and projected public norms of Yale culture. Furthermore, he assumes at least the following: (1) that Yale students are integrated in their social groups and classrooms; (2) that normative subjects would find authoritative the arguments of those constructed as their social subordinates; (3) that it would be safe for one who is marginalized to speak out against their classmates in public space; and (4) that it is the responsibility of marginalized and stereotyped groups to educate those who benefit from marginalizing and stereotyping them.

In defense of the Christakises' position, Professor Alan Jacobs of Baylor University argues that any Yale student who seeks an environment on campus akin to a home is bound to be disappointed. Residential colleges, he notes, are places where "people from all over the world, from a wide range of social backgrounds . . . come to live together temporarily. [They are] essentially public space," he adds, "though with controls on ingress and egress to prevent chaos and foster friendship and fellowship" (2015; emphasis in original). Many scholars take a different route, not calling into 
question the desire to feel at home, but by challenging the assumption that "discomfort impedes learning" (Barrett 2010; Boostrom 1998; hooks 1989, 1994; Stengel 2010) and framing the positive pedagogical value of critique and disagreement. They allege that such safe spaces can in some instances censor critical reflection, replace sympathy with sentimentality, turn open-mindedness into empty headedness, and deny important differences existing among students (Boostrom 1998). Discomfort, they argue, serves an indispensable role in sharpening students' perspectives and analytical skills. Students should, they admit, feel "safe enough"-but not necessarily comfortable- to voice their opinions and critically respond to their peers and instructors (Boostrom 1998).

Here I would like to make two points. First, recognizing educational space as by definition unsafe does not function to diminish the worth of safe spaces. Rather it can be a starting point for considering the ambiguous discursive terrain of pedagogical safe space. Instead of denying danger, safe space begins with recovering the legitimacy of fear and the deconstruction of the social imagery that simultaneously creates and supports a world organized around separation. The classroom in this instance offers up an invitation to interpret and respond to conflict (Stengel 2010). Discursive, pedagogical safe space is therefore not static, but a perpetual movement between safe and unsafe, individual and collective, agreement and disagreement. Safe spaces allow "individuals in a collective environment ... [to] be empowered to encounter risk on their own terms," knowing that these risks will vary based upon experience, but that they will not have to justify their right to experience (Hunter 2008, 18-19). In this conception, space becomes a codeword for the process of the ever-becoming of messy negotiations of identity and practice in motion (Hunter 2008).

Some practical examples may be instructive here. In my experience as Women's and Gender Studies professor, I actively engage in the process of creating safe(r) space in my classrooms from the first day of the semester. Some basic techniques I have acquired throughout my career include: allowing students to say their names first rather than calling them off of a roll, explaining the student code of conduct which prohibits harassment based on social identity, and describing what is required of them and what they can expect from me in a class where discussion is used as a common pedagogical tool. The first technique was developed through my own engagement in an optional development course on trans inclusivity in the classroom and from actively reading transfeminist research on preventing marginalization of trans students on college campuses (see Nicolazzo 2016). As a nontrans person, I had to acknowledge my experiential limits in considering what practices would best facilitate the opportunity for trans students to accurately name themselves, without having to identify themselves as trans to others if they do not so desire. I had to consider the way in which the space of the classroom is occupied not just by the people who comprise it at any given time, but what frames how we encounter one another (students and professors, students and students) from the beginning of the semester. How does power accrue to students who do not have to speak up and identify themselves as already mis-identified and what do I have to do in order to disrupt these normative functions? The practical purpose of these questions and the developed practice is to facilitate safe(r) spaces for trans students to identify themselves as trans if they wish to do so, but the effect is much broader in that it functions as a recognition that the "official roll" reinforces classroom and campus space as cisnormative through enacting a barrier for trans students to being accurately identified. While universities vary in terms of how they update student records, many universities require student records (and all that is derived from this record) to match one's "legal" identity. Thus, if a trans student has not legally changed their name, they are often misnamed and misgendered until they do so. Now, in making this change to my teaching practice I have not erected a force field that will protect trans students from cissexism and transphobia during their time at the university, but I have actively intervened in the cisnormative functioning of the university and indicated something to all of the students about the 
space we will all occupy together for the semester. An unintended, though not surprising, effect of this practice has been expressions of gratitude not just from trans students, but from students who have had their names mispronounced by (predominantly white) professors and teachers from primary through postsecondary schooling. I mention this here because it shows an important point, namely that as soon as we begin to interrogate the normative organization of space and its consequences for one marginalized group, the space itself is disclosed to us not just through or in the terms that we expect (i.e. as cisnormative), but as constituted by multiple systems simultaneously. While these initial constitutional practices are important, the handling of course materials that are "unsafe" for marginalized students also deserves our attention. Again, I will draw from my own experience in creating safe $(\mathrm{r})$ classrooms, with the acknowledgment that this example is more specific and while still adaptable, as all course materials are constructed within social worlds, perhaps less amenable to directly assume.

Generally, debates about course content and safe spaces tend to collapse into debates regarding whether or not "trigger warnings" need to be given when professors assign "sensitive" materials, where sensitive generally means that a text employs racist language or employs explicit description(s) of sexual violence. I am not interested in centreing debates on trigger warnings here, but I will note that trigger warnings and calls for them are symptoms of something deeper. They are not the goal in and of themselves. This should become clear through my example in that I do not use "trigger warnings" 7 as they are commonly conceived. Rather, I build the space in which the harmful materials will be encountered in a way that enables access by the students who experience potential harm(s) through the materials themselves.

In a course, entitled "Gender, Race, and Science," my students and I unpack the masculinist, anti-black racist, cissexist, heteronormative, classist, and ableist epistemological frameworks and methodological practices of the natural and social sciences. Unsur- prisingly, the depth and breadth of sexism and racism in the history of science is formidable. But, for many marginalized students, even those who are women's and gender studies majors, confronting the history of the sciences as well as contemporary epistemological frameworks and practices can be disorienting and potentially traumatic. My concerns inevitably centre upon black women's possible experiences in the class due to the abuse and disparagement of black women that has occurred throughout the history of science and medicine. Further adding to the potential harm is the fact that this history lives with us today in terms of the failures to address the health inequities that black women face and the use of sexist and racist stereotyping to justify these inequities. In short, I was and still am concerned that the materials in this course could cause black female students to retreat inward, when what I desire for them are liminal moments that, while dangerous, are full of potentiality for change. Yet, I know these moments will be impossible, if I do not model, from day one, an anti-racist and anti-sexist classroom atmosphere.

The first step is choosing materials from black feminist writers who are aware of the harm that the use of racialized and sexist images can cause in their black female readers. Thus, when we cover the historical use of Sarah Bartmann as a "specimen" for furthering scientific justification for categorizing women as inferior to men and black peoples as a species apart from white people, we simultaneously read an excerpt from Patricia Hill Collins' Black Feminist Thought (2000) which details the sexual politics of black womanhood. In a chapter entitled "The Sexual Politics of Black Womanhood," Collins criticizes the historical use of Bartmann within a racist scientific project and the way Bartmann's image is still used by contemporary scholars in their presentations on their research. She describes several approaches the various scholars take in prepping or failing to prep their audiences for the image of Bartmann they intend to project on the screen. Two of the examples are from men's work (one white and one black). The white male scholar, whom Collins frames as having "done much to challenge scientific racism" through his work, left an image of 
Bartmann on screen for several minutes while he told jokes about "the seeming sexual interests of White voyeurs of the 19th century" $(2000,142)$. This is while black women panelists sat on either side of him, positioned directly in front of the projection of Bartmann herself. By projecting the image of Bartman in this way and while on a panel with prominent black scholars, the white male scholar functioned to invite the audience members to become voyeurs of Bartmann, reinscribing her, and by extension the black women panelists, as objects while he projected his own agenda. Collins notes she questioned him about his pornographic use of Bartmann's image and his response featured references to "free speech" and the "right" to use public domain material however he so desired. What was missing from his response, and notably from the Christakises' and others who champion racist speech and costuming, was a concern for the harm he effected against black women through his active contribution to their continued objectification.

The second scholar, a black man, used Bartmann's image similarly in a presentation on the changing size of Black bodies in racist iconography. Collins writes: "Once again, the slide show began, and there she was again. Sarah Bartmann's body appeared on the screen, not to provide a humourous interlude [as in the case of the white male scholar], but as the body chosen to represent the nineteenth-century 'raced' body" (2000, 142). Collins poses a similar question to the black male scholar regarding the purpose of encouraging the audience to engage in a lengthy voyeuristic gaze at a pornified image of Bartmann. His reply, while not centred on abstract norms of "rights" and "free speech," was also telling and dismissive. Rather than considering her criticism, the black male scholar suggested that she missed the deep point of his presentation and stated he was concerned about race and not gender, thus reifying blackness and the harms black people face as harms against black masculinity.

The third scholarly use of an image of Bartmann described by Collins is by a prominent white female feminist scholar. This scholar, by contrast, adequately prepares her audience for the image she is about to show, noting as she does that graphic images of black women's objectification and dehumanization cause great harm to audience members. Collins admires her thoughtfulness, but, at first, believes her to be "overly cautious," that is, until she sees the reactions of young black female students seeing Bartmann's image for the first time (2000, 141). Many young black women in the audience cried and Collins recognized they were linking the pornographic treatment of Bartmann as displayed in these images with their own contemporary experiences of racialized, sexual surveillance.

The scientific objectification and debasement of black women is not merely historical, but exists alongside a contemporary order where black women are pornographically objectified and reduced. To act as if it were a bygone problem of bad science is to neglect contemporary black female students and potentially set them up for being disenfranchised in the classroom. Fortunately, I read Black Feminist Thought prior to entering the classroom as an instructor and have used the theoretical content and her descriptive anecdotes to create my classroom. The theory presented by Collins challenges the students by posing a threat to the normative constructs and assumptions within which students safely reside. How we use Collins work, inserting it into our coverage of a racist and sexist history of scientific practice, can function to provide a safe(r) space for black female student to engage with the materials. ${ }^{8}$

Returning to Jacobs' argument, namely that students should not expect safety reserved for private spaces, like homes, in public spaces such as university dormitories and campuses, I think we can now see that the notion of the university as necessarily failing to be a home for all students ignores the socio-spatial reality of public space as imagined and continuously (re)iterated. Put more concisely, the university already exists and continues to be remade in its existence as a home for some students, namely those with normatively valued social identities. Arguing we should not act in order to make space comfortable for those who regularly experience discomfort in public space is not a 
neutral argument. On the contrary, it is a call to (re)iterate public space in order to support those who regularly experience recognition through denying that possibility to marginalized groups. This is, of course, not to suggest that all persons confirmed as members of normative identities are valued. Rather, the binary of safe versus unsafe can be further challenged or "troubled" by looking at the ways in which space is not "safe" for all persons who engage in heterosexual practices. Cohen's (1997) discussion of "welfare queens" and Collins' discussion of black heterosexuality as deviant $(1990 ; 2000)$ are two examples. According to Cohen, the welfare queen presumably engages in or has engaged in normative heterosexual practices to varying degrees and thus should be valued within the dominant (heterosexual) world. Yet, she is not accepted because she has not performed heterosexuality appropriately. First and foremost, the welfare queen is imagined to be black, and black sexuality, as Cohen shows, is defined as dangerous, as a threat to whiteness and white peoples. Second, she is poor and within neoliberal, capitalist orders, poor women who reproduce are rendered irresponsible and thus a drain on the dominant system. Finally, she is unmarried and thus fails to perform the patriarchal norm of sexuality as contained within the heterosexual marriage bond. Thus, while the welfare queen participates in the norm of heterosexuality, her heterosexual practices are not valued within dominant space and she is cast out as deviant. By contrast, commercial and urban space has been expanded to be "safe" for some homonormative identities (often white, upper/middle class, gay men) resulting in some queer subjects arguing that safe spaces are no longer necessary. Individual components of social identity, then, do not function to position groups as universally oppressed or universally privileged, but are complex in their dependence upon the ways systems intersect and how identities are assembled together. Space is complex and attention to this complexity does not eliminate the exchange of ideas, but enables an awareness of the framework that plays a role in the formation and expression of knowledge, power, and justice. By providing access to the critical framework in which our encounters occur, our students are able to think more deeply about the social world they occupy and the kinds of theories and practices they come to utilize. Collins' and Cohen's examples force us to confront the ways in which seemingly normative identities that should be "safe" to occupy in public space become "unsafe" through intersecting with identities deemed undesirable and deviant. Deliberating upon the ways in which identities themselves can be simultaneously and paradoxically constituted by "safety" and "deviancy" can then facilitate a better understanding of the backlash that students like the "Shrieking Girl" face as they seek to raise their voices for equity.

One of the dominant criticisms expressed in conservative media coverage and on social media of this student of colour (the "Shrieking Girl") is that she is privileged" in terms of class and thus should stop whining about an issue as trivial as Halloween costumes. The language used to criticize this student is clearly gendered and racialized (she is described in blogs as shrieking, aggressive, unhinged, delusional, and as part of a mob that accosted Christakis). ${ }^{10}$ In representing her in this manner, her criticism, that Christakis has a general responsibility to attend to students' safety as a professor at Yale and more specifically as a resident master who lives among students at Silliman Hall in order to serve as a direct contact and guide for them, is ignored. Furthermore, in concentrating upon her inappropriate "behaviour," Nicholas Christakis' defensiveness, as well as her implicit claim regarding how the constitution of space at Yale University manifests through power discrepancies are erased. Yet, the erasure of these components of the exchange is telling and is, in effect, part of the problem of the idea of neutrality itself. The exchange between Christakis and the student could never be neutral because he is already constituted in space as a rational, masculine-identified, academic whose argument is read as a refusal to put some students ahead of others and instead facilitate learning for all. By contrast, as a female of colour, the student was inevitably framed through gendered and racialized stereotypes, while simultaneously being cast as "privileged" because she attends Yale. Simply put, the politics of space were engaged yet unacknowledged in the media 
coverage of this exchange, with the effect of rendering the student challenger as non-existent in her claim. How she is erased is notable: it is through making her hypervisible as a woman of colour that she, as a subject making a claim, is rendered absent. As Lewis Gordon explains in Bad Faith and Antiblack Racism, "the more present a black is, the more absent is this 'something.' And the more absent a black is the more present is this something. ... In this formulation, then, the black's absence fails to translate into his human presence" (1999, 98; emphasis in original). Invisibility of black people within antiblack racist societies is not new; it constitutes black people in their chattel roles under racialized enslavement and within colonial societies. But how black people are rendered invisible is significant for they are invisible not in-and-of-themselves (i.e. they are seen). Rather, their humanity is made invisible and they are regarded "as mere objects of the environment, mere things among things" (Gordon 1999, 98). The student's situation is ironic. As she makes claims, asserts herself, she is viewed in a way that is not seen as herself. She is not seen as an individual, her humanity is missed, evaded, and she goes misrecognized as she is recognized merely as black and woman. To see her as a female student of colour is to not see her at all.

To return to the student's claim, to make her present as human rather than a racialized and gendered bodyobject, her argument is not merely that Christakis should be fired or ashamed of himself, but rather that he is explicitly not engaging in a neutral act when he calls for students to "talk to one another." Christakis is, she asserts, protecting white students at the expense of marginalized students of colour under the guise of color-blindness. Applying Gordon's analysis (1999; 2015), white students on Yale's campus are already present as human; it is the students of colour whose identities are constituted by ironic hypervisibility and absence. Thus, when we act in order to further uphold the humanity of white students' abstract rights to learn, we do so at the further expense of marginalized students whom we expect to not only ignore the continuous dehumanization they experience, but we require they center the humanity of the persons who cause their dehumanization. The creation of safe(r) spaces, of course, will not remedy the history of the erasure of the humanity of people of colour. But the generative act and subsequent actions that sustain safe(r) spaces can function to subvert, through deconstruction of the normative functioning of identities within space, the continuation of said erasure through appeal to "neutrality" as a value.

In the next section I will use the consideration of complex identities as they occupy space developed thus far to address a criticism of queer theory as an appropriate resource for building safe(r) spaces. Specifically, some scholars have argued that in calling for safe space for marginalized groups, queer theory negates one of its central tenets, namely, that identity is a mere artifact of discourse. Thus, a question we must attend to in calling for safe(r) space is: Can queer theory remain faithful to its epistemological premises by dismantling social contingency in some cases (e.g., gay and lesbian subject positions) while recuperating social contingency in others (e.g., racialized subject positions)? Or put differently, what does queer theory provide as a resource to critical race theory and feminist theory in understanding what safe $(r)$ spaces are and how they function as liberatory?

\section{Safe(r) Spaces as Queer Spaces}

Queer theory as a discipline "troubles" the heterosexist, patriarchal, and race-blind assumptions built into sociological renderings of the subject, thus providing a more complex understanding of the subject position and the process of subject formation. Furthermore, queer theory shows how heteronormativity in concert with systems of race, class, and gender are woven together to reinforce hegemonic normativity that requires assimilation and similarity, rather than the uncertainty of partial, messy, and incomplete difference (Rodriguez 2003). Understanding the intersecting regulatory nature of race, gender, and sexuality is, in my mind, necessary to develop antioppressive practices that incorporate queer theories. 
Queer theorists, beginning with Foucault, argue the subject is irreducible to an ontological self. The implication is that modern subjectification produces the appearance of subjects that represent closures in the performative interval. In Foucault (1980), after all, the modern same-sex oriented person is both a creation in discourse and in excess of the text once constituted. In Butler (1993; 1997) we see a similar argument regarding the status of the gender self and the lesbian self. Thus, in terms of identity, queer theory destabilizes the idea of the pre-constituted sexual, gendered, and racial subject and reframes the function of power as productive rather than simply oppressive.

Yet, in calling for safe spaces where women, persons of colour, and queer people are able to negotiate their social identities and the misrecognition they suffer, critics claim we fall back on the principles of an epistemology that requires the formulation of a subject with an intact, stable interiority. Without a commitment to the ontology of the self, this line of criticism continues, how does one identify the phenomenology of race, sexuality, and gender? For these critics it seems that queer theoretical currents that specifically aspire to "recuperate" non-European identities (Halberstam 2005; Jagose 1996), racialized subject positions, feminist subjectivities, and queer identities (Barnard 2004; Perez 2015) cannot simultaneously maintain deconstructionist epistemological position. On the other hand, theorists like Henry (2000) and Gordon (1999) are right to worry that the postmodern turn toward language as the source (and effect) of power and identity can obscure the functions of formal authorities, including political parties, elections, and corporate elites, thus potentially inducing political nihilism.

However, arguing for the instability of identity is not commensurate to arguing that social identity does not matter. Social identity categories can be both constructions and effects of power and can be solidified externally to create and maintain barriers to recognition and participation. Put differently, the instability of identity is not always actively chosen. When it is not chosen by a subject who seeks meaning in and through transgressing normative boundaries, but rather is placed upon one as an effect of a normative system, then the subject can experience oppression in seeking recognition and/or participation (Butler 2004). One's gender, race, or sexual orientation may not ontologically be the product of an inherent interiority, but nevertheless these categories function to map possibilities in social space for individuals identified as gendered, raced, and sexually oriented (Fanon 1967; Gordon 1999). For normative identities, space can open up around the self, enabling more options and a positive conception of a self as embraced and reflected in the dominant world. But, for those who fall outside the lines of normative identity, space becomes limiting, often negatively impacting available concrete options as well as the way one represents oneself. Thus, the effects of marginalization are tangible even if social identities are performative effects that must be constantly reiterated in order to exist. For this reason, among others, recuperating identity is required to repair the damage of self and community perpetuated by the repeated degradation of marginalized identity (Fanon 1967; Gordon 1999).

I propose, however, that the instability of identity and the understanding of identity as inherently unstable can queer the space of the classroom in a positive manner through the recuperation of marginalized identities. Furthermore, I contend that the concrete practice of creating safe(r) spaces on university campuses can inform the ostensible theoretical impasse described above. Consider what we have covered in previous sections. If spaces are not ever truly neutral, but are constructed and reconstructed through the effect(s) of power as it works on and within those spaces, then space itself is able to be remade through active interventions. Reading critical race theory, feminist theory, and queer theory together here can be quite instructive. Common critiques offered through black feminist and critical race theories (and black feminist critical race theories) reveal the reification of blackness through social structuring that is both formal and informal. "Black" and "blackness" 
are linguistic abstractions imprinted with meaning that is mapped onto black peoples in a manner that is imprecise. The same is true regarding the concept of "whiteness" and explains how populations can be culturally "whitened" and why it may be possible to describe devalued class and gender populations as "black." But, as critical race theorists who reject postmodern sensibilities argue, to leave the reality of "blackness" in the realm of ideas and language is to fail to adequately capture the black person as a problem in the antiblack world. The black person is not just read or understood through the idea of blackness, but is taken to be really black in their being - to such an extent that their entire being becomes a problem. Thus, the black person's being is not unstable but reified as metastable. Furthermore, although the mapping of blackness onto people may be imprecise, it is not arbitrary. The black body is taken to be not just a sign of inferiority, but truly inferior. To diminish this point is to fail from the outset to create truly safe(r) spaces for people of colour in that it erases the lived history of the body as racialized. Take the example of Bartmann again: She, as a black woman, is erased as a human being, but is reified as her body. Her blackness is her inferiority existing in her body and her body is also the sign of her inferiority. But the shame of the black female students who are forced to publicly view Bartmann's body alongside others is not abstract; it is not a linguistic concept, but is felt in their body, because her body is their body. Thus, to appreciate the experience of the lack of safety that black female students encounter here, we need the account of a critical race theorist (or a queer theorist with critical race sensibilities) because shame is an embodied experience that occurs through feeling the degrading gaze of the other. Yet this experience is also an effect of power that is diffuse, a point that post-modernist queer theories help us understand.

In producing safe $(\mathrm{r})$ space in the classroom, we are morally required to respond to particular constructions and imaginations of what is "unsafe" for our students, but we can also expose those constructions as the products of discourses that can be reimagined through adopting new classroom policies and through re-orienting ourselves in our roles as professors and administrators. Just as we have moved to understand gender, racial, and sexual stratification as more than the oppression and subordination of one group over and against another, we can come to understand safe space as something more than simply a response to a static and predefined category of "unsafe." Like the work performed in challenging and reconfiguring binaries in feminist theory, critical race theory, and queer theory, a reconceptualization of safe space as argued in this essay understands the safety of the space as fluid, in constant negotiation, and never complete. Thus, we achieve a spatial organization that does not "protect" students from the unjust world outside (or a history of injustices), but rather allows for the bracketing of harm induced to allow them to analyze critically the systems that surround and affect them. In other words, by paying attention to the cisnormative construction of space that occurs through calling roll, by considering the voyeurism we implicitly invite in showing pornographic images of black women in class, and by deconstructing the way in which "neutrality" is a tool that empowers normative identities at the expense of marginalizes ones, we actively recreate spaces that provide room for the expansion of nonnormative peoples to be more than just their identities as imposed.

Furthermore, the experience created in "safe" classrooms provides intellectual space for critical thought for normative identities as well. White students, male students, and straight identifying students are not left out. Rather, they are given the opportunity to learn and engage deeply with critical theories (and their fellow students) in order to further their intellectual and moral lives. Take for example what has happened when I have made the materials on the study of Bartmann safer for black female students. Through using black feminist perspectives to unpack and name the racialized harms enacted on Bartmann and black women generally, black female students studying the materials felt more comfortable to discuss the ways in which politics and scientific modes of inquiry intersect both historically and contemporarily. While this was notably my aim, the ways they dis- 
cussed the scientific voyeurism enacted on and against Bartmann was not quite what I had imagined initially. Inevitably, however, this discussion has served the class better than I could have predicted. For rather than discussing Bartmann's vulva, breasts, and steatopygia, they discussed the politics of black women's hair and how it is has been used to frame black people as "dirty," as "unkempt," and black women as less culturally desirable and valuable than white women. The politics of hair was a safe(r) framework through which black female students could analyze racist and sexist scientific theories and practices because they did not have to objectify themselves as pornographic racialized objects for the class in order to learn. Now, this does not mean that black female students were fully safe in this space. Discussing the way in which black women's hair, their hair, is used against them is still painful for black women, but for the students this was a safer way that they chose to consider objectification, hierarchies of sexuality, race, and gender in science, and the intersection of politics and science. Additionally, the black female students were aware of the shift they performed through naming this focus of discussion as their explicit intent when they were asked about the connection between black hair and the materials on Bartmann. One black female student explained that she felt more comfortable talking about the way black women's hair is framed by white people than she was discussing the way black women's sexuality and bodies are treated by white people. Another black female student noted that entitlement to black women's hair and their bodies are the same, but that talking about hair is easier than talking about the way her body and other black women's bodies are objectified and reduced. In setting up the possibility for greater comfort for black women in the classroom, I helped to create more options for them. As a result, they were able to lead the conversation in a way that reinforced their ability to learn the materials. For other students who are not black women, the assigned black feminist scholarship, coupled with the voices of the black women who led discussion in the classroom, allowed them to understand more deeply how systems intersect to oppress black women under the guise of science.
Pedagogically safe spaces extend a further benefit to all students, namely that of operating from an understanding of the embodiment of the historical subject. Traditional classrooms, by contrast, preserve a mind/body split that detaches a theorist or speaker's physical embodiment (and relationship to power) from their theoretical position. In doing so, the traditional classroom fails to attend to the socio-historical production of ideas and thus leaves students unable to evaluate critically and analytically the whole context. Instead, they are asked to accept uncritically the history of knowledge as handed down from a god's eye position, which can prevent them from seeing science, philosophy, economics, literature-all disciplines — as engaged in confronting problems that face human beings in their lived experiences. Showing students the relationship of theorists to power, formal and informal, enables students to examine more objectively the world in which they live, its production, and contemporaneous arguments fashioned by theorists, politicians, and pundits. Additionally, and again this is beneficial for all students, classrooms constructed to be safe spaces enable critical interrogation of self and the sources of our learning. Without the opportunity to see the self as located historically and socially in space, we prevent students from understanding processes of meaning and knowledge production.

To outsiders, it may appear as though professors who value the cultivation of safe space are hindering the free exchange of ideas. And even if students with normative identities feel as though they are unable to speak absolutely freely, this is not necessarily an obstruction of learning but an opportunity for deeper understanding. A white student, male student, or straight-identified student who has considered raising their hand, but then opted not to out of concern for how they may be viewed, can use this experience to reflect upon why their intended question or comment is problematic in terms of the course material thus far. In that moment, they have demonstrated their understanding, and then can reflect upon the question themselves, write about their experience in a reflection paper for the course, or come to office hours to discuss. The options for this student are still many. Fur- 
thermore, even if the student decides to ask the question, the professor and other students will help them unpack the question critically. In other words, despite the notion of dominant students being ridiculed "for saying the wrong thing" often performed in abstract dialogues about safe spaces, students who belong to dominant groups are not in practice derided for asking questions. Quite to the contrary, in my experience the students who "use the wrong language" in discussing gender and sexuality/sexual orientation or "express views" steeped in racist and classist ideologies are often shown by marginalized students who are harmed by said rhetoric (and, of course, more specifically the implications of the rhetoric itself in creating space and policy) the issues with the language or viewpoint being expressed. Now, is the student who "uses the wrong language" or who expresses a "problematic view" that relies on racist/sexist stereotypes always convinced by the arguments presented? No, of course not. But, this hypothetical student is able to access a deeper connection to the course materials, which does benefit him in terms of his potential grade. Further, the fact that the marginalized student has responded in an insightful way demonstrates that the student feels "safe enough" to do so. That said, students in my courses, and other courses similar to those I teach, tend not to use outright racist, sexist, transphobic, homophobic slurs in the classroom regardless of whether I cultivate a safe space or not. Except for the rare exceptions, students who have made it their mission to disrupt or even troll in the classroom, students are concerned with the way their fellow students see them in class and thus save their more controversial points for written work that only I will read. Rather, what is more common is the uncritical deployment of problematic stereotypes and ideas about the world, which students have acquired through living in a society that is white-normative, sexist, capitalist, and heteronormative.

\section{Concluding Thoughts}

To conclude, then, the changes that occur in a safe space classroom are twofold. First, all students within safe(r) space classrooms learn to interrogate systems of power, including performative public spaces, as important to the theories and perspectives being taught. They learn that all systems are created and maintained, rather than natural and absolute, and they learn to see the ambiguities of political and social life that dominant systems attempt to abject. Then, they are able to begin to ask how said systems are propped up and who benefits from the dominant institutional organization. If they themselves do not benefit, they can begin to build concrete strategies for revealing and dismantling the contradictions of said political, social, and economic systems. If they do benefit, they can then ask themselves if they want to be the beneficiaries of an unjust order wherein which they gain individually through the exploitation and marginalization of others, thus contributing to the dismantling of these contradictions through the revelation of the activity of dominant groups in the construction of spatial power constructs. In the end, even if they do not particularly care about the suffering of others, at least they will have been required to confront the reality of this attitude in themselves.

The second change is in the experiences of historically marginalized students. In safe space classrooms, these students come to understand that they have the power to respond if a student with more normative power-power that is constituted through an effect of matching dominant attitudes and ideals of identity outside of the classroom-makes a claim that reinforces racist ideology, sexism, or heteronormativity. Historically marginalized students also know it is not always their responsibility to represent the marginalized group to which they belong. This can be experienced as burdensome; the student must always be on edge, ready to respond to their fellow classmates who fail to understand the underlying racist, sexist, transphobic, etc. systems that make possible their ideas and comments. Such a burden can also create circumstances where it is easier for the individual student to adopt strategies and attitudes that do not serve necessarily serve them. As Fanon argues in Black Skin, White Masks (1967), people whose identities are nonnormative have generally two choices. They can ask 
the dominant group not to notice their blackness (and by extension, for our purposes, their femininity and/or queerness), or they can concede the badness of blackness and the goodness of the whiteness. Neither of these options produce equity for the non-normative person or group. Within the first negotiation, neutrality becomes the dominant force, and we have seen what neutrality produces in space when the construction of space fails to be interrogated. But with the second choice, there are two further general paths one may take. One may seek to recuperate the value of blackness by showing that blackness is really good; or one may accept the badness of blackness and use it against other black people to "put them in their place" when they have gone astray according to white standards. Regardless of which way the black person turns or which attitude they adopt, whiteness holds all the cards and functions as "the gaze of the third" (Gordon 1999). By contrast, in a safe space classroom, the marginalized student learns and then knows that the professor will take on that work, will serve as the "third," and will not enable racist or transphobic ideas to be presented equivalent in their worth as anti-racist or trans-inclusive ideas. Yet while I am always there to intervene, in practice I rarely have to, at least by the end of the semester. Rather, the students, through the active work of the cultivation of the safe space classroom, have come to participate in dynamic dialogue because they feel supported by one another. Thus, far from shutting down dialogue, safe spaces often make dialogue more likely because these spaces remove, albeit not perfectly or absolutely, the alienation marginalized students often experience. And normative students often use their personal experiences of alienation from a team, from family members, from friends, and so forth within this opened space to connect to the experiences of marginalized students. And while we clearly unpack the difference between these forms of suffering and institutional oppression, the openness of the normative students, the way in which they render themselves vulnerable in order to connect with their classmates and the materials, contributes positively and importantly to the shared space.
In short, I contend that we do a disservice to our students, especially our marginalized ones, in reifying the mind/body split to preserve systems of "neutrality" and "objectivity," which invariably turn out to be not so neutral or objective at all. I do not pretend students will always "get it right" and at times they will over-apply or over-extend theories and practices, but these instances, too, are learning experiences for both those who "call out/call in" and those who are "called out/called in." To encourage these experiences with deep critical dialogue, we need to do better at defending safe spaces as theoretical and pedagogical resources. When politicians, journalists, pundits, and professors who are not experts in critical race theory, feminist theory, or queer theory occupy the most recognized voices in commenting on safe spaces, the content and function of safe spaces become confused and diminished. Students generally have less power than these aforementioned voices and thus become ridiculed or dismissed as overzealous or absurd. Yet it is our marginalized students that we should be listening to because they have a view of systematic expression of marginalization from all sides: both as members of said university community, trying to succeed within that community, and as marginalized subjectivities that do not fit comfortably within the system. 


\section{Endnotes}

1. See for example coverage of the refusal of University of Toronto professor Jordan Peterson to use gender pronouns that correspond with gender identity if they do not "match" what he, Professor Peterson, deems to be their readable gender. Here, the invocation of free speech entails reference to the right not to be compelled to/in speech.

2. See coverage of the support and outrage expressed by UK academics and students regarding the call by the higher education minister, Jo Johnson, for all British universities to protect "free speech" on college campuses as a policy and practice or face fines. Here, free speech is generally invoked to protect conservative and xenophobic perspectives on immigration.

3. For a copy of the email from the Intercultural Affairs Committee at Yale see: https://www.thefire.org/email-from-intercultural-affairs/.

4. For a copy of the email penned by Dr. Christakis see: https://www.thefire.org/email-from-erika-christakis-dressing-yourselves-email-to-silliman-college-yalestudents-on-halloween-costumes/.

5. Realistically, the motivation for issuing an administrative recommendation is at least in part based in concern regarding the bad publicity the university would face in light of a headline describing racist student parties.

6. To view the exchange see: https://www.youtube.com/watch v=9IEFD_JVYd0\&feature=youtu.be.

7. This is not to suggest that I am opposed to trigger warnings. I think they certainly do serve their purpose in courses/environments where the time to actively recreate space is not possible due to mitigating or external factors.

8. It perhaps goes without saying, but I do not show Bartmann's image or other similar pornographic im- ages of black women (or any marginalized group) in class, nor do I assign readings featuring such images. I have had white male students state in class that they "wish they had images to reference in reading/covering these materials to make the points more clear." I rarely need to offer an explanation, however, as the black women in the class provide quite insightful explanations based in experience and theory regarding why such images would be deeply problematic in class. I include this example as it also shows that white male students are not silenced in safe $(r)$ space classrooms. They clearly feel comfortable enough to request access to such images even after we have covered the problems with the public viewing of said images. But what has shifted through creating safe(r) space for black women in the class is they feel supported enough to respond and they are not attacked after they respond (which also requires a certain form of attention to the cultivation of classroom space itself).

9. See https://dailycaller.com/2015/11/09/meet-theprivileged-yale-student-who-shrieked-at-her-professor/.

10. For some examples see http://victorygirlsblog.com/yale-shrieking-girl-identified-as-jerelyn-luther-video/; https://www.nationalreview.com/2017/05/americanuniversities-true-purpose-transmitting-knowledge/; http://time.com/5395131/college-bias-kavanaugh-diversity/. Even op-eds meant to offer a defense of the student(s) confronting Christakis note that it would be easy to watch the video and deem her/them aggressive and unreasonable. See for example https://www.cnn.com/2015/11/12/opinions/kohn-yaleprotests/index.html. 


\section{References}

Ahmed, S. 2004. The Cultural Politics of Emotion.

New York, New York: Routledge.

. 2006. Queer Phenomenology. Durham, NC:

Duke University Press. 2010. The Promise of Happiness. Durham, NC:

Duke University Press.

Alcoff, L. 1998. "Cultural Feminism versus

Poststructuralism: The Identity Crisis in Feminist

Theory." Signs Vol. 13 (3): 405-36.

Barnard, I. 2004. Queer Race: Cultural Interventions in the Racial Politics of Queer Theory. New York, NY: Peter Lang Publishing.

Barrett, Betty J. 2010. "Is 'Safety' Dangerous? A Critical Examination of the Classroom as Safe Space." Canadian Journal for the Scholarship of Teaching and Learning 1 (1) http://dx.doi.org/10.5206/cjsotlrcacea.2010.1.9

Bell, D. and Valentine, G. 1995. Mapping Desire: Geographies of Sexualities. London: Routledge.

Bergoffen, D. 1992. "Casting Shadows: The Body in Descartes, Sartre, De Beauvoir and Lacan." Bulletin de la Societe Americane de Philosopher de Language Francaise 4, (2-3): 232-243.

Binnie, J. 1997. "Coming Out of Geography: Towards a Queer Epistemology?" Environment and Planning D: Society and Space 15: 223-37.

Boostrom, R. 1998. "Safe spaces: Reflections on an Educational Metaphor." Journal of Curriculum Studies 30 (4): 397-408.

Brady, J. and Audrey Denitith. 2001. "Critical Voyages: Postmodern Feminist Pedagogies Liberatory Practice." Teaching Education 12 (2): 165-176.
Buffington, M. and Alice Lei. 2011. "Resistance and Tension in Feminist Teaching." Visual Arts Research 37 (2): $1-13$.

Butler, J. 1993. Bodies That Matter. New York, NY: Routledge. 1997. Excitable Speech: A Politics of the Performative. New York, NY: Routledge. . 2004. Undoing Gender. New York: NY: Routledge.

Cohen. C. 1997. "Punks, Bulldaggers, and Welfare Queens: The Radical Potential of Queer Politics." GLQ: A Journal of Lesbian and Gay Studies 3 (4): $437-$ 475.

Collins, P. 1990; 2000. Black Feminist Thought:

Knowledge, Consciousness and the Politics of Empowerment. New York: Routledge.

Davis, A. 1981. Women, Race, and Class. New York: Vintage.

Du Bois, W.E.B. 1969. The Souls of Black Folk. New York: Signet Classics.

Fanon, F. 1967. Black Skin, White Masks. Translated by Charles Lamm Markmann. New York: Grove Press.

Foucault, M. 1980. Power/Knowledge: Selected Interviews and Other Writings. New York, NY: Random House Books.

Fox, C. 2010. “(Un)Covering Normalized Gender and Race Subjectivities in LGBT 'Safe Spaces." Feminist Studies 36 (3): 629-649.

Gordon, L. 1999. Bad Faith and Antiblack Racism. Amherst, New York: Humanity Press. 2015. What Fanon Said: A Philosophical Introduction to His Life and Thought. New York, NY: 
Fordham University Press.

Gutmann, A. 1994. Multiculturalism and the Politics

of Recognition. Princeton, N.J.: Princeton University Press.

Jacobs, A. 2015, November 9. Safe Homes and Public Individuality at Yale. Retrieved from https://www.theamericanconservative.com/jacobs/saf e-homes-and-public-individuality-at-yale/

Jagose, A. 1996. Queer Theory. New York, NY: New York University Press.

Halberstam, J. 2005. In a Queer Time and Place. New York: NYU Press.

Henry, P. 2000. Caliban's Reason: Introducing AfroCaribbean Philosophy. New York, NY: Routledge.

Honneth, A. 1992. "Integrity and Disrespect: Principles of a Conception of Morality Based on the Theory of Recognition.” Political Theory 20 (2): 187201.

1996. The Struggle for Recognition. The Moral Grammar of Social Conflicts. Cambridge: Polity Press.

hooks, b. 1981. Ain't I a Woman?: Black Women and Feminism. Boston: South End Press. 1989. Talking Back: Thinking Feminist, Thinking Black. Boston: South End Press.

1994. Teaching to Transgress: Education as the Practice of Freedom. New York, NY: Routledge.

Hubbard, P. 2008. "Here, There, Everywhere: The Ubiquitous Geographies of Heteronormativity." Geography Compass 10: 1-19.

Hunter, M. 2008. "Cultivating the Art of Safe Space." Research in Drama Education: The Journal of Applied Theatre and Performance 13 (1): 5-21.
Karabel, J. 2005. "How Affirmative Action Took Hold at Harvard, Yale, and Princeton." The Journal of Blacks in Higher Education 48 (Summer): 58-77.

Koskela, H. 1997. "Bold Walk and Breakings: Women's Spatial Confidence versus Fear of Violence." Gender, Place and Culture 4 (3): 301-319.

Ludlow, J. 2004. "From Safe Space to Contested Space in the Feminist Classroom." Transformations: The Journal of Inclusive Scholarship and Pedagogy 15(1): 40-56.

Mahraj, K. 2010. "Dis/locating the Margins: Gloria Anzaldua and Dynamic Feminist Learning." Feminist Teacher 21 (1): 1-20.

Marini, Z. 2009. "The Thin Line between Civility and Incivility: Fostering Reflection and Self-awareness to Create a Civil Learning Community." Collected Essays on Teaching and Learning 2: 61-67.

Nicolazzo, Z. 2017. Trans* In College: Transgender Students' Strategies for Navigating Campus Life and the Institutional Politics of Inclusion. Sterling, VA: Stylus.

Perez, H. 2015. A Taste for Brown Bodies: Gay Modernity and Cosmopolitan Desire. New York, NY: NYU Press.

Puar, J.K. 2006. "Mapping US Homonormativities." Gender, Place and Culture 13: 67-88.

Revilla, A. 2010. "Raza Womyn-Making it Safe to Be Queer: Student Organization as Retention Tools in Higher Education." Black Women, Gender \& Families 4 (1): 37-62.

Rodriguez, J. 2003. Queer Latinidad: Identity Practices, Discursive Spaces. New York, NY: New York University Press.

Rodriguez, N. 2016. Critical Concepts in Queer Studies and Education: An International Guide for the Twenty-first Century. Boston, MA: Harvard University Press.

Issue $39.2 / 2018$ 
Stengel, B. and Lisa Weems. 2010. "Questioning Safe Spaces: An Introduction." Studies in Philosophy and Education 29 (6): 505-507.

Stengel, B. 2010. "The Complex Case of Fear and Safe Space." Studies in Philosophy and Education 29 (6): 523-540.

Toynton, R. 2006. "Invisible Other: Understanding Safe Spaces for Queer Learners and Teachers in Adult Education." Studies in the Education of Adults 38: 178-194.

Valentine, G. 1989. "The Geography of Women's Fear." Area 21(4): 385-390. . 1990. "Women's Fear and the Design of Public Space." Built Environment 16 (4): 288-303. . 1992. "Images of Danger: Women's Sources of Information about the Spatial Distribution of Male Violence." Area 24 (1): 22-29. . 2000. "Sticks and Stones May Break My Bones': A Personal Geography of Harassment." Journal of Lesbian Studies 4: 81-112. . 2007. "Theorizing and Researching Intersectionality: A Challenge for Feminist Geography." The Professional Geographer 59: 1-21.

Weems, L. 2010. "From Home to Camp: Theorizing the Space of Safety." Studies in Philosophy and Education 29 (6): 557-566.

Young, I. M. 1990. Justice and the Politics of Difference. Princeton, N.J.: Princeton University Press. 